\title{
First-line treatment patterns and lipid target levels attainment in very high cardiovascular risk outpatients
}

\author{
Ioanna Xanthopoulou, Periklis Davlouros, Simos Siahos, Angelos Perperis, Evangelia Zaharioglou
} and Dimitrios Alexopoulos*

\begin{abstract}
Objectives: Previous studies have demonstrated gaps in achievement of low-density lipoprotein-cholesterol (LDL-C) goals among patients at very high cardiovascular risk. We aimed to investigate lipid treatment patterns, rates and predictors of lipid targets attainment, in such outpatients in an urban area of Greece.

Methods: This was a prospective observational study, conducted in 19 outpatient clinics of Western Greece. We recruited patients with established cardiovascular disease (CVD) and/or diabetes mellitus (DM), previously (at least 3 months before baseline assessment) untreated with any lipid lowering medication. Lipid profile assessment was performed at baseline (prior to lipid-lowering treatment initiation) and at follow-up. Lipid lowering treatment choice was at physicians' discretion and was kept constant until follow-up.

Results: We recruited 712 patients with a mean age $61.4 \pm 10.4$ years, 68.0\% males, 43.0\% with DM, 64.7\% with prior coronary artery disease-CAD. In total, $237 / 712$ (33.3\%) of prescribed regimens were of high or very high LDL-C lowering efficacy and out of them 113/237 (47.7\%) comprised a combination of statin and ezetimibe. At follow-up the primary target of $\mathrm{LDL}-\mathrm{C}<70 \mathrm{mg} / \mathrm{dL}(1.8 \mathrm{mmol} / \mathrm{L})$ was achieved in $71(10.0 \%)$ patients. The secondary target of non-HDL-C $<100 \mathrm{mg} / \mathrm{dL}(2.6 \mathrm{mmol} / \mathrm{L})$ in the subgroup of patients with DM or increased triglycerides levels (>150 mg/dl or $1.7 \mathrm{mmol} / \mathrm{L}$ ) was achieved in 45(11.6\%) of patients. In multivariate logistic regression analysis (AUC $=0.71,95 \%$ Cls 0.65-0.77, p < 0.001) male gender, smoking, baseline LDL-C and very high potency LDL-C lowering regimen emerged as independent predictors of LDL-C goal attainment $(\mathrm{OR}=1.88,95 \% \mathrm{Cls} 1.03-3.44$, $\mathrm{p}=0.04, \mathrm{OR}=0.57,95 \% \mathrm{Cls} 0.33-0.96, \mathrm{p}=0.04, \mathrm{OR}=0.98,95 \% \mathrm{Cls} 0.98-0.99, \mathrm{p}<0.001$ and $\mathrm{OR}=2.21,95 \% \mathrm{Cls}$ 1.15-4.24, $\mathrm{p}=0.02$ respectively).
\end{abstract}

Conclusions: First-line management of dyslipidemia among very-high cardiovascular risk outpatients in Western Greece is unsatisfactory, with the majority of treated individuals failing to attain the LDL-C and non-HDL-C targets. This finding points out the need for intensification of statin treatment in such patients.

Keywords: Statin, LDL-C target attainment, Non-HDL-C target attainment, Very high cardiovascular risk

\footnotetext{
* Correspondence: dalex@med.upatras.gr

From the Department of Cardiology, Patras University Hospital, Patras,
}

Rion 26500, Greece

\section{Biomed Central}

(c) 2013 Xanthopoulou et al.; licensee BioMed Central Ltd. This is an open access article distributed under the terms of the Creative Commons Attribution License (http://creativecommons.org/licenses/by/2.0), which permits unrestricted use, distribution, and reproduction in any medium, provided the original work is properly cited. 


\section{Introduction}

Cardiovascular disease (CVD) is the leading cause of global mortality, accounting for more deaths annually than any other cause [1]. Modification of the risk factors related to CVD, such as dyslipidemia, smoking, or a sedentary lifestyle, has been shown to reduce CVD mortality and morbidity [2].

It has been demonstrated that low density lipoproteincholesterol (LDL-C) reduction by statins substantially reduces cardiovascular morbidity and mortality in both primary and secondary prevention [3-5]. In 2004 the National Cholesterol Education Program Adult Treatment Panel III (NCEP-ATP III) guidelines were updated with the addition of the optional goal of LDL-C $<70 \mathrm{mg} / \mathrm{dL}$ $(1.8 \mathrm{mmol} / \mathrm{L})$ for those patients considered to be at very high cardiovascular risk, mainly based on evidence from Heart Protection Study (HPS) and The Pravastatin or Atorvastatin Evaluation and Infection Therapy (PROVE IT) trials [6-8]. Subsequently, Incremental Increase in End Points Through Aggressive Lipid Lowering (IDEAL) and Treating to New Targets (TNT) studies provided evidence that more intensive versus moderate LDL-C lowering treatment reduces the risk of major cardiovascular events in patients with coronary artery disease (CAD) $[9,10]$. A recent meta-analysis of several clinical trials involving $>170,000$ patients revealed a dosedependent reduction in CVD morbidity and mortality with LDL-C reduction [3]. Accumulating evidence with respect to the beneficial effect on clinical outcome of intensified statin therapy led the 2011 European Society of Cardiology (ESC)/European Atherosclerosis Society (EAS) guidelines to adopt LDL-C $<70 \mathrm{mg} / \mathrm{dL}(1.8 \mathrm{mmol} / \mathrm{L})$ as the main treatment goal in the subgroup of patients considered to be at very high cardiovascular risk [2].

However, despite cumulating data from large clinical trials demonstrating the benefit of LDL-C goal achievement, which is recommended by the guidelines, a significant treatment gap still remains, especially in patients considered at very high cardiovascular risk: National Cholesterol Education Program Evaluation ProjecT Utilizing Novel E-Technology (NEPTUNE) and Lipid Treatment Assessment Project 2 (L-TAP 2) trials, which were conducted between 2003 and 2007, showed that only 17.8\%-34\% of very high risk patients attained the optional goal of $\mathrm{LDL}-\mathrm{C}<70 \mathrm{mg} / \mathrm{dL}(1.8 \mathrm{mmol} / \mathrm{L})[11,12]$. It would be interesting to assess lipid lowering management after the release of the 2011 ESC/EAS guidelines.

The present study aimed to investigate lipid-lowering drug therapy used in every-day clinical practice, rates and predictors of treatment target attainment among outpatients with established CVD and/or diabetes mellitus (DM), considered to be at very-high cardiovascular risk in an urban area of Greece.

\section{Methods}

This was a prospective, observational study, conducted between June 2011 and January 2012, in the county of Achaia, Western Greece (327,316 inhabitants in 2001), in 17 private and 2 public ( 1 tertiary and 1 regional hospital) outpatient cardiology clinics. We identified patients with established CVD and/or DM, previously (at least 3 months before baseline assessment) untreated with any lipid lowering medication.

Patients with established CVD were considered those with known CAD or non-coronary forms of atherosclerotic disease: peripheral arterial disease (PAD), abdominal aortic aneurysm, cerebrovascular disease (ischemic stroke/ transient ischemic attack or $>50 \%$ obstruction of a carotid artery on ultrasound). CAD was defined as any of the following: prior myocardial infarction (MI), prior percutaneous coronary intervention (PCI) or coronary artery by-pass grafting (CABG), documented unstable angina, positive non-invasive stress testing (nuclear imaging or stress echocardiography) or $\geq 50 \%$ stenosis of at least one major coronary artery on angiography. Presence of PAD was determined by a history of intermittent claudication, decreased pulses or bruit with ankle-brachial index $<0.90$, or abnormal duplex ultrasound. DM was defined as preexisting diagnosis of DM made by a physician, use of oral-hypoglycaemic agents or insulin or 2 fasting glucose measurements $>126 \mathrm{mg} / \mathrm{dL}$ [13].

Lipid profile assessment was performed at baseline (prior to initiation of any lipid-lowering treatment) and at followup. Data extracted from patient's medical records were collected and a case report form was completed. Only patients with complete lipid profile data [total cholesterol (TC), LDL-C, high-density lipoprotein-cholesterol (HDL-C) and triglycedides (TG)] at baseline and at follow-up were included in analyses. Lipid lowering treatment choice as well as lipid level monitoring and response to treatment was at clinicians' discretion. Lipid-lowering treatment was kept constant until lipid profile assessment at follow-up and patients with treatment changes were excluded from analysis. Lipid assessment was performed in commercial laboratories, in the context of usual clinical practice, under fasting conditions. HDL-C was measured directly in the serum. Friedewald formula was used for LDL-C calculation [14]. Non-HDL-C was calculated as TC minus HDL-C. Patients with known familial hypercholesterolemia or TG > $400 \mathrm{mg} / \mathrm{dL}$, were excluded from the present analysis.

Primary treatment target was LDL-C $<70 \mathrm{mg} / \mathrm{dL}$ $(1.8 \mathrm{mmol} / \mathrm{L})$, as the studied population was considered to be at very high cardiovascular risk. Reiner Z, 2011 [2] Non-HDL-C $<100 \mathrm{mg} / \mathrm{dL}(2.6 \mathrm{mmol} / \mathrm{L})$ was a secondary treatment target, in the subgroup of patients with DM or increased TG levels (>150 mg/dL or $1.7 \mathrm{mmol} / \mathrm{L})$ [2].

Lipid lowering regimens were classified by their \% LDL-C reduction efficacy, according to dose and kind of 
statin used and whether ezetimibe was prescribed as an adjunct (combined therapy with ezetimibe and a statin was considered to provide an incremental reduction in LDL-C of 15\%). As shown in Table 1, four groups of lipid lowering regimens were identified: low, moderate, high and very high-efficacy group, which included regimens producing $\leq 30 \%, 31-45 \%, 46-55 \%$ and $>55 \%$ LDL-C reduction respectively [2]. Lipid lowering regimens with at least low, moderate, high, or very high-efficacy were considered as an appropriate treatment selection to achieve the goal of LDL-C $<70 \mathrm{mg} / \mathrm{dL}(1.8 \mathrm{mmol} / \mathrm{L})$ at follow-up, in patients with baseline LDL-C $<100,100-130,131-150$ and $>150 \mathrm{mg} / \mathrm{dL}$ respectively.

Study's protocol was approved by Patras University Hospital Ethics Committee and all participants gave written informed consent.

\section{Statistical analysis}

Categorical data are presented as frequencies and group percentages and continuous data as means \pm standard deviation. Two-sample t-test and the Fisher's exact test were used for comparison of continuous and categorical data respectively. Multivariate logistic regression analysis (in a backward elimination fashion, $\mathrm{p}>0.1$ for removal) was used to assess independent predictors of LDL-C goal attainment at follow-up, controlling for age, gender, diabetes mellitus, presence of CAD, PAD, cerebrovascular disease, smoking at baseline assessment, baseline LDL-C, combined therapy with ezetimibe and a statin and very high potency LDL-C lowering regimen. Fenofibrate and $\mathrm{n} 3$ fatty acids use were additionally investigated as potential predictive factors of non-HDL-C goal attainment. Models were tested for discriminative power by the $\mathrm{C}$ statistic [area under the receiver operating characteristic (ROC) curve]. All tests were 2-tailed and statistical significance was considered for $\mathrm{p}$-values $<0.05$. Statistical analyses were performed using SPSS for Windows (version 16.0 SPSS Inc.Chicago II USA).

\section{Results}

\section{Study population}

The study population consisted of 712 outpatients (mean age $61.4 \pm 10.4$ years, $68.0 \%$ males). Patients' baseline characteristics and lipid values by LDL-C goal attainment at follow-up are depicted in Table 2. Lipid profile assessment at follow-up was performed at a median time of 3.0 (2.9-3.3 first to third quartile) months. The majority (64.7\%) of patients had prior CAD, $43.0 \%$ of them were diabetics and $54.1 \%$ were current smokers, with a mean LDL-C of $167.0 \pm 35.6 \mathrm{mg} / \mathrm{dL}$ at time of baseline assessment. As shown in Figure 1, at baseline only $1(0.1 \%)$ patient had no lipid disorders, whereas 709 (99.7\%) patients had LDL-C $\geq 70 \mathrm{mg} / \mathrm{dL}(1.8 \mathrm{mmol} / \mathrm{L})$.

Table 1 Classification of lipid lowering regimens used by their LDL-C lowering efficacy

\begin{tabular}{|c|c|c|c|c|}
\hline & Low \% LDL-C reduction & Moderate $\%$ LDL-C reduction & High \% LDL-C reduction & Very high \% LDL-C reduction \\
\hline \multirow[t]{4}{*}{ Simvastatin } & $10 \mathrm{mg}$ & $10 \mathrm{mg}+$ Eze & & $40 \mathrm{mg}+$ Eze \\
\hline & & $20 \mathrm{mg}$ & $80 \mathrm{mg}$ & \\
\hline & & & $20 \mathrm{mg}+$ Eze & $80 \mathrm{mg}+$ Eze \\
\hline & & $40 \mathrm{mg}$ & & \\
\hline \multirow[t]{2}{*}{ Fluvastatin } & $40 \mathrm{mg}$ & $80 \mathrm{mg}$ & & \\
\hline & & & $80 \mathrm{mg}+$ Eze & \\
\hline \multirow[t]{5}{*}{ Rosuvastatin } & & $5 \mathrm{mg}$ & $20 \mathrm{mg}$ & $5 \mathrm{mg}+$ Eze \\
\hline & & & & $10 \mathrm{mg}+$ Eze \\
\hline & & & $10 \mathrm{mg}$ & $20 \mathrm{mg}+$ Eze \\
\hline & & & & $40 \mathrm{mg}$ \\
\hline & & & & $40 m g+E$ \\
\hline \multirow[t]{3}{*}{ Pravastatin } & $20 \mathrm{mg}$ & $20 \mathrm{mg}+$ Eze & & \\
\hline & $40 \mathrm{mg}$ & $40 \mathrm{mg}+$ Eze & & \\
\hline & & $80 \mathrm{mg}$ & & \\
\hline \multirow[t]{3}{*}{ Atorvastatin } & & $10 \mathrm{mg}$ & & $20 \mathrm{mg}+$ Eze \\
\hline & & $20 \mathrm{mg}$ & $40 \mathrm{mg}$ & $40 \mathrm{mg}+$ Eze \\
\hline & & $20 \mathrm{mg}$ & $10 \mathrm{mg}+$ Eze & \\
\hline Ezetimibe & $10 \mathrm{mg}$ & & & \\
\hline Fenofibrate & $200 \mathrm{mg}$ & & & \\
\hline
\end{tabular}

Eze = ezetimibe. 
Table 2 Baseline characteristics of study population

\begin{tabular}{|c|c|c|c|c|}
\hline & Overall $\mathrm{N}=712$ & LDL-C goal attainment $\mathrm{N}=71$ & No LDL-C goal attainment $\mathrm{N}=641$ & $\mathrm{p}$-value \\
\hline Age (years) & $61.4 \pm 10.4$ & $63.2 \pm 11.3$ & $61.2 \pm 10.3$ & 0.1 \\
\hline Male gender & $484(68.0)$ & $55(77.5)$ & $429(66.9)$ & 0.08 \\
\hline \multicolumn{5}{|l|}{ Cardiovascular risk factors } \\
\hline Prior CAD & $461(64.7)$ & $53(74.6)$ & $408(63.7)$ & 0.07 \\
\hline Cerebrovascular disease & $64(9.0)$ & $1(1.4)$ & $63(9.8)$ & 0.01 \\
\hline Abdominal aortic aneurysm & $24(3.4)$ & $8(11.3)$ & $55(8.6)$ & 0.5 \\
\hline Peripheral arterial disease & $63(8.8)$ & $8(11.3)$ & $55(8.6)$ & 0.5 \\
\hline Hypertension & $458(64.3)$ & $44(62.0)$ & $414(64.6)$ & 0.7 \\
\hline Smoking & $385(54.1)$ & $29(40.8)$ & $356(55.5)$ & 0.02 \\
\hline Diabetes mellitus & $306(43.0)$ & $27(38.0)$ & $279(43.5)$ & 0.4 \\
\hline Family history of CAD & $164(23.0)$ & $13(18.3)$ & $151(23.6)$ & 0.4 \\
\hline \multicolumn{5}{|l|}{ Lipid levels at baseline } \\
\hline $\mathrm{TC}(\mathrm{mg} / \mathrm{dl})$ & $248.5 \pm 37.3$ & $232.7 \pm 36.9$ & $250.3 \pm 36.9$ & $<0.001$ \\
\hline LDL-C (mg/dl) & $167.0 \pm 35.6$ & $150.1 \pm 34.5$ & $168.8 \pm 35.3$ & $<0.001$ \\
\hline $\mathrm{HDL}-\mathrm{C}(\mathrm{mg} / \mathrm{dl})$ & $45.7 \pm 11.3$ & $46.6 \pm 10.1$ & $45.6 \pm 11.4$ & 0.5 \\
\hline TG (mg/dl) & $165.2 \pm 68.4$ & $170.7 \pm 79.8$ & $164.6 \pm 67.0$ & 0.5 \\
\hline Non HDL-C (mg/dl) & $202.9 \pm 37.7$ & $186.1 \pm 37.7$ & $204.7 \pm 37.3$ & $<0.001$ \\
\hline
\end{tabular}

Data are expressed as means $\pm S D$ or $n(\%)$. CAD $=$ coronary artery disease, $T C=$ total cholesterol, $L D L-C=$ low-density lipoprotein-cholesterol, $\mathrm{HDL}-\mathrm{C}=$ high-density lipoprotein-cholesterol, $\mathrm{TG}=$ triglycerides.

\section{Lipid lowering treatment patterns}

Lipid lowering regimens used included the following antilipidemic drug classes: statins, fibrates, ezetimibe and n3 fatty acids. Statin monotherapy was the most frequently prescribed regimen (65.3\%) while $29.0 \%$ of patients were prescribed a combination of statin and ezetimibe at the baseline visit (Table 3). Simvastatin was the most frequently prescribed statin (Figure 2). The majority of patients received a regimen of moderate LDL-C lowering efficacy overall and in each baseline LDL-C subgroup of patients (Figure 3). In total, only 237/712 (33.3\%) of prescribed regimens had appropriate LDL-C lowering efficacy, out of them $113 / 237(47.7 \%)$ comprised a combination of statin and ezetimibe.
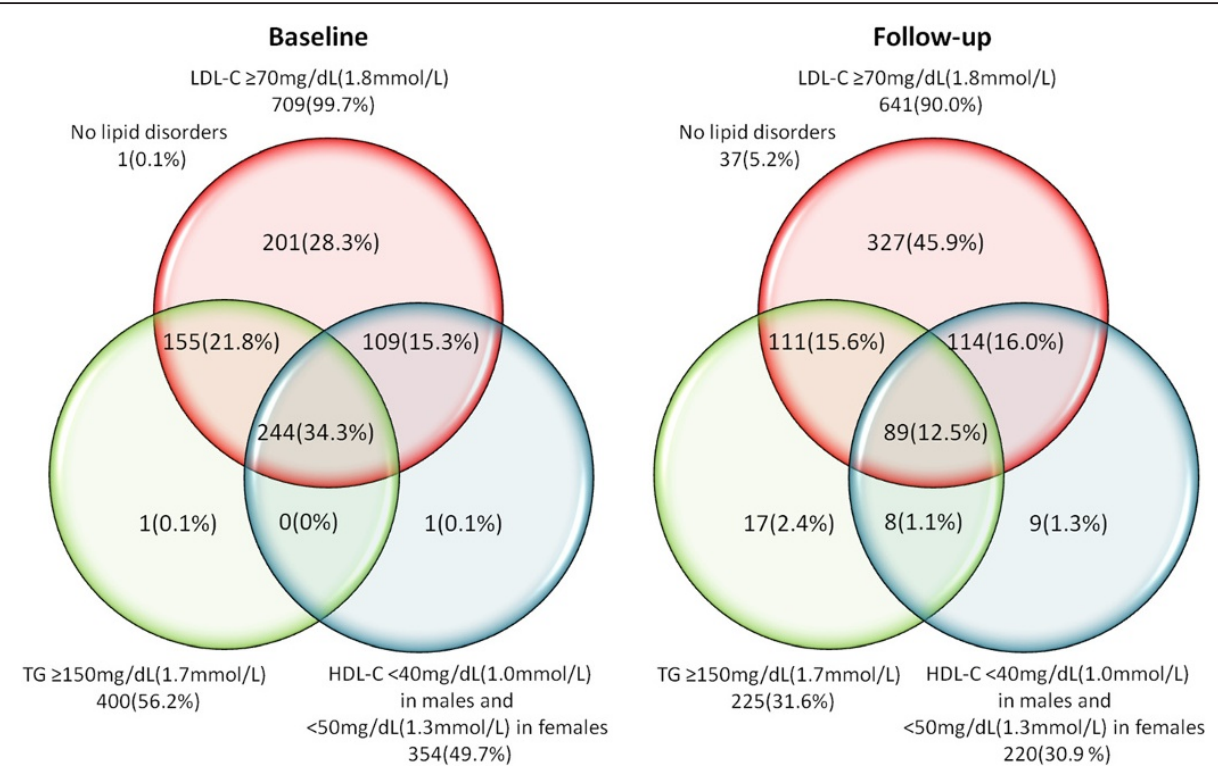

Figure 1 Lipid disorders rates before initiation of lipid modifying treatment and at follow-up. 
Table 3 Lipid modifying treatment of study population

\begin{tabular}{|c|c|c|c|c|}
\hline & Overall $\mathrm{N}=712$ & LDL-C goal attainment $\mathrm{N}=71$ & No LDL-C goal attainment $\mathrm{N}=641$ & $\mathrm{p}$-value \\
\hline Monotherapy & $476(66.9)$ & $43(60.6)$ & $433(67.6)$ & 0.2 \\
\hline Statin & $465(65.3)$ & $43(60.6)$ & $422(65.8)$ & 0.4 \\
\hline Fibrate & $4(0.6)$ & $0(0)$ & $4(0.6)$ & 1.0 \\
\hline Ezetimibe & $7(1.0)$ & $0(0)$ & $8(1.2)$ & 1.0 \\
\hline Combination therapy & $236(33.1)$ & $28(39.4)$ & $208(32.4)$ & 0.2 \\
\hline Statin + Ezetimibe & $182(25.6)$ & $22(31.0)$ & $160(25.0)$ & 0.3 \\
\hline Statin + Ezetimibe + n3 fatty acids & $24(3.4)$ & $2(2.8)$ & $22(3.4)$ & 1.0 \\
\hline Statin + n3 fatty acids & $24(3.4)$ & $2(2.8)$ & $22(3.4)$ & 1.0 \\
\hline Other & $6(0.8)$ & $2(2.8)$ & $4(0.6)$ & 0.1 \\
\hline$\%$ LDL-C reduction efficacy & & & & 0.5 \\
\hline low & $42(5.9)$ & $4(5.6)$ & $38(5.9)$ & \\
\hline moderate & $486(68.3)$ & $45(63.4)$ & $441(68.8)$ & \\
\hline high & $160(22.5)$ & $18(25.4)$ & $142(22.2)$ & \\
\hline very high & $24(3.4)$ & $4(5.6)$ & $20(3.1)$ & \\
\hline
\end{tabular}

Data are expressed as $\mathrm{n}(\%)$.

\section{Treatment target attainment at follow-up}

At follow-up the primary target of LDL-C $<70 \mathrm{mg} / \mathrm{dL}$ $(1.8 \mathrm{mmol} / \mathrm{L})$ was achieved in $71(10.0 \%)$ patients. In total 389 patients were eligible for the secondary target of non HDL-C, which was achieved in 45(11.6\%) of them. Figure 1 shows rates of all lipid disorders at baseline and at follow-up.

\section{Multivariate analysis}

In multivariate logistic regression analysis ( $\mathrm{AUC}=0.71$, 95\%CIs 0.65-0.77, $\mathrm{p}<0.001$ ) male gender, smoking, baseline LDL-C and very high potency LDL-C lowering regimen emerged as independent predictors of LDL-C goal attainment $(\mathrm{OR}=1.88,95 \% \mathrm{CIs} 1.03-3.44, \mathrm{p}=0.04, \mathrm{OR}=$
0.57, 95\%CIs 0.33-0.96, $\mathrm{p}=0.04$, OR $=0.98,95 \%$ CIs 0.98 $0.99, \mathrm{p}<0.001$ and $\mathrm{OR}=2.21,95 \% \mathrm{CIs} 1.15-4.24, \mathrm{p}=0.02$ respectively). There was a trend towards lower rates of LDL-C goal attainment in patients with cerebrovascular disease $(\mathrm{OR}=0.15,95 \% \mathrm{CIs} 0.02-1.14, \mathrm{p}=0.07)$, as seen in Table 4. Baseline LDL-C (OR $=0.98$, 95\%CIs 0.97-0.99, $\mathrm{p}<0.001)$ emerged as the only independent predictor of non-HDL-C target attainment (AUC $=0.69$, 95\%CIs $0.62-0.77, \mathrm{p}<0.001)$, as seen in Table 5.

\section{Discussion}

This prospective, observational study provides insights into the lipid lowering treatment of outpatients at very high cardiovascular risk in Western Greece. The main

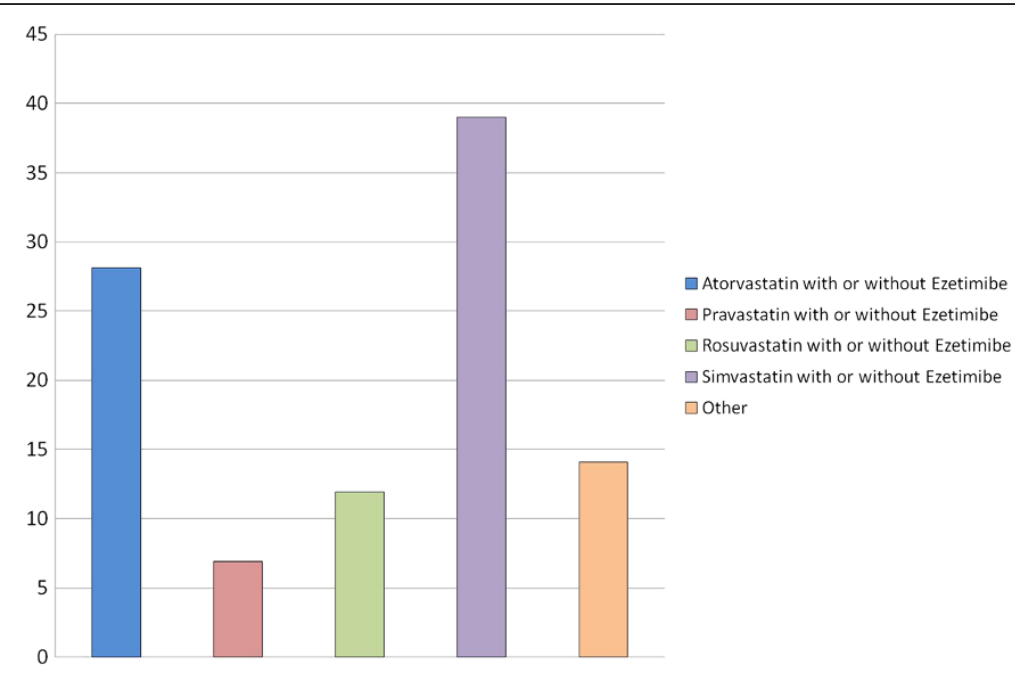

Figure 2 Lipid modifying medications used in the study population, category "other" includes regimens representing $<1 \%$ of all prescribed treatments. 


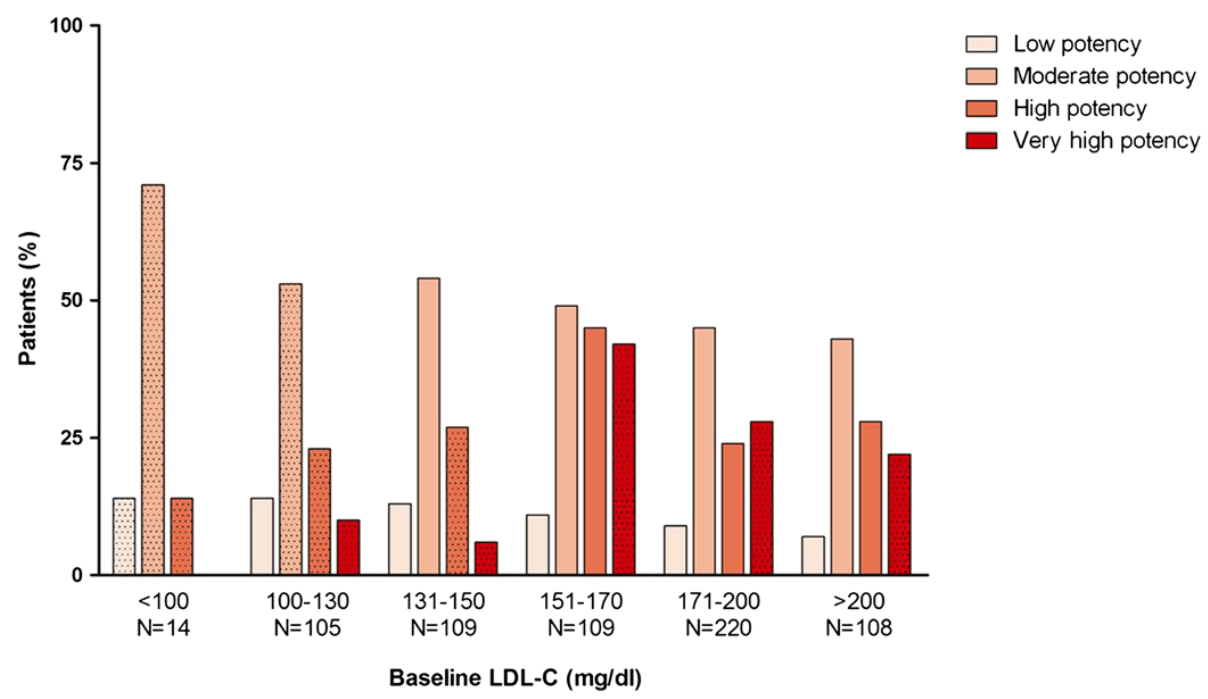

Figure 3 LDL-C lowering potency of lipid lowering therapy by baseline LDL-C, bars represent percentages within each baseline LDL-C subgroup. Dotted pattern indicates treatment appropriateness as a function of baseline $L D L-C$ to achieve the target of $L D L-C<70(1.8 \mathrm{mmol} / L)$ at follow-up.

findings of our study are: a) Current first-line management of dyslipidemia seems to be unsatisfactory, since most of the treated individuals failed to attain the LDL-C target at follow-up b) In the majority of patients, prescribed lipid lowering regimens had a suboptimal LDL-C $\%$ reduction efficacy, as a function of baseline LDL-C, to attain the goal of $<70 \mathrm{mg} / \mathrm{dl}(1.8 \mathrm{mmol} / \mathrm{L})$. c) Approximately $1 / 3$ of patients were prescribed a combination of statin and ezetimibe as first-line lipid-lowering treatment. Our study points out a significant therapeutic gap in treatment of patients at very high cardiovascular risk, mainly due to prescription of suboptimal lipid lowering regimens.

Based on several randomized clinical trials $[3,9,10]$, current ESC guidelines recommend LDL-C $<70 \mathrm{mg} / \mathrm{dL}$ $(1.8 \mathrm{mmol} / \mathrm{L})$ as the primary treatment target in patients at very high cardiovascular risk [2]. However, observational studies show that only a small proportion of patients with CAD achieve this goal [15-18]. A survey which included longitudinal data from 18,656 participants, showed that in U.S. achievement of LDL-C $<70 \mathrm{mg} / \mathrm{dL}$ $(1.8 \mathrm{mmol} / \mathrm{L})$ improved from $2.4 \%$ to $17 \%(\mathrm{p}<0.0001)$ in high-risk individuals and patients with CAD (3.4\% to $21.4 \%, \mathrm{p}<0.0001$ ) over the last decade, but still remains insatisfactory [19]. Our findings are in the same line of evidence, with the vast majority of patients failing to attain LDL-C treatment target.

Several reasons may contribute to this observed treatment gap. First, underestimation of cardiovascular risk by the treating physician could have resulted in a poor LDL-C target choice, leading to a lipid-lowering treatment of suboptimal efficacy. As shown by Sager et al. in

Table 4 Predictors of LDL-C goal attainment

\begin{tabular}{lccc}
\hline & \multicolumn{1}{c}{ Initial model } & & Final model \\
\hline Male gender & $\mathrm{OR}(95 \% \mathrm{Cls})$ & P-value & OR (95\% Cls $)$ \\
Age & $1.66(0.88-3.13)$ & 0.1 & $1.88(1.03-3.44)$ \\
DM & $1.02(0.99-1.04)$ & 0.3 & \\
Smoking & $0.92(0.49-1.76)$ & 0.8 & 0.04 \\
CAD & $0.62(0.36-1.07)$ & 0.09 & $0.57(0.33-0.96)$ \\
PAD & $1.34(0.65-2.77)$ & 0.4 & 0.04 \\
Cerebrovascular disease & $1.53(0.65-3.58)$ & 0.3 & $0.15(0.02-1.14)$ \\
Baseline LDL-C (mg/dl) & $0.14(0.02-1.004)$ & 0.05 & $0.99(0.98-0.99)$ \\
Combined therapy with statin and ezetimibe & $0.99(0.98-0.99)$ & $<0.001$ & 0.07 \\
Very high potency LDL-C lowering regimen & $1.15(0.56-2.34)$ & 0.7 & $<0.001$ \\
\hline
\end{tabular}


Table 5 Predictors of non HDL-C goal attainment

\begin{tabular}{lccc}
\hline & \multicolumn{1}{c}{ Initial model } & & Final model \\
\hline Male gender & OR (95\% Cls $)$ & P-value & OR (95\% Cls) \\
Age & $1.04(0.50-2.17)$ & 0.9 & \\
DM & $1.01(0.98-1.05)$ & 0.4 & 0.6 \\
Smoking & $0.78(0.33-1.87)$ & 0.2 & $1.80(0.95-3.42)$ \\
CAD & $0.65(0.31-1.36)$ & 0.2 & 0.07 \\
PAD & $1.61(0.75-3.45)$ & 0.3 & $0.98(0.97-0.99)$ \\
Cerebrovascular disease & $1.71(0.62-4.66)$ & 0.5 & $<0.001$ \\
Baseline LDL-C (mg/dl) & $0.64(0.17-2.35)$ & 0.001 & 0.1 \\
Combined therapy with statin and ezetimibe & $0.98(0.97-0.99)$ & 0.9 & \\
Very high potency LDL-C lowering regimen & $1.92(0.81-4.56)$ & 0.9 & \\
Fenofibrate & $1.06(0.36-3.10)$ & & \\
n3 fatty acids & $1.05(0.34-3.42)$ & & \\
\hline DM & & & \\
\hline
\end{tabular}

$\mathrm{DM}=$ diabetes mellitus, $\mathrm{CAD}=$ coronary artery disease, $\mathrm{PAD}=$ peripheral arterial disease, $\mathrm{LDL}-\mathrm{C}=$ low density lipoprotein-cholesterol.

a study which evaluated 907 physicians' perception of guideline-recommended low-density lipoprotein target values, approximately $50 \%$ of high-risk patients did not receive correct assignment of LDL target by their physicians [20]. In addition, lack of awareness of the new, more aggressive target of LDL-C $<70 \mathrm{mg} / \mathrm{dL}(1.8 \mathrm{mmol} / \mathrm{L})$ by the treating physicians, could have lead to the suboptimal management of dyslipidemia in these patients [21]. However, failure to initiate a lipid lowering treatment of appropriate efficacy is probably the main reason for the observed low treatment goal attainment in our population. Indeed, only $33.3 \%$ of patients were prescribed a lipid lowering regimen of appropriate efficacy, finding is in accordance with other observational studies [20-22].

It is of note that in our study, a significant proportion of patients did not receive statin monotherapy but a combination of statin and ezetimibe as starting treatment. This can be explained by reluctance of physicians to prescribe statins at high doses by the fear of side effects like myotoxicity [22] and by evidence supporting a stronger LDL-C lowering effect of combination therapy with statin and ezetimibe versus statin monotherapy [23-26]. Statin treatment is in general considered safe and serious adverse events are rare. However, mainly in individuals with comorbidities, statin treatment may lead to myopathy, a potentially fatal condition $[2,22]$. Statins may also lead to transaminase elevation, which is dosedependent and usually reversible by reduction of dose [2]. Ezetimibe provides when combined with a statin an incremental reduction in LDL-C levels of $15-20 \%$ and can be used as a combination with statins, in patients with poor statin tolerance [2].

Male gender and treatment with very high potency LDL-C lowering regimen favored primary treatment target attainment, consistently with previous reports $[17,27,28]$.
In addition, our multivariate analysis showed that current smokers and those with higher baseline LDL-C were less likely to achieve LDL-C target, also in accordance with other studies [11,17,21,29].

Furthermore, our study showed that success rate for the secondary target of non-HDL-C was also very low. Evaluation of success in attaining non-HDL-C goal in the multinational L-TAP 2 study revealed a 34\% success rate among patients at very high cardiovascular risk, however among those patients who failed to attain their LDL-C target in the overall population only $11.2 \%$ achieved the non-HDL-C target [12]. Therefore, the very low success rate of non-HDL-C observed in our study might be explained by the poor LDL-C goal achievement.

The low treatment goal attainment among patients at very high cardiovascular risk, underscores the need to improve management of dyslipidaemia in those patients. Treatment intensification with selection of appropriate dose and drug as first-line treatment as well as dose titration when needed will help translating the important benefits that statins demonstrated in large-scale clinical trials to the real world.

Our study underscores the need to use a statin (at the appropriate dose) as first-line treatment of dyslipidemia. Otherwise, suboptimal dosing may lead to a high proportion of patients not achieving the LDL-C goal. These therapeutic options are clearly highlighted in the 2011 ESC/EAS guidelines, which recommend that a statin should be the first-line pharmacological treatment of dyslipidaemia, prescribed at a dose capable to provide the percentage LDL-C reduction to achieve the LDL-C target for patient's individual CV risk level. If LDL-C target is not achieved after dose titration, statin combination with bile acid sequestrant, nicotinic acid or cholesterol absorption inhibitor may be considered [2]. In addition, 
the ongoing large outcome trials: Improved Reduction of Outcomes: Vytorin Efficacy International Trial (IMPROVEIT) and Efficacy and Safety of Alirocumab SAR236553 (REGN727) Versus Placebo on Top of Lipid-Modifying Therapy in Patients With High Cardiovascular Risk and Hypercholesterolemia (ODYSSEY Combo I) will provide important information on the role of combined lipidlowering therapy in the treatment of patients at high cardiovascular risk.

Several limitations apply to our study. As we only studied patients managed by a cardiologist our findings may not reflect the practices of other physicians. Furthermore, our results may underestimate the prevalence of lipidlowering treatment failure in the general population, as selection of participating physicians and patients was based on their consent and complete lipid profile availability. In addition, as our study was conducted shortly after the release of 2011 ESC/EAS guidelines, we cannot exclude the existence of potential temporal trend in perception of guidelines and management of dyslipidaemias by the treating physicians. Allowing a longer interval before recheck lipid levels is probably considered as an "off-label" practice. However, no evidence based information exists and low rates of goal attainment at follow-up, could certainly not be attributed to inadequate treatment length. We did not use a central laboratory for lipid measurements; however this rather reflects the real-life clinical practice. Finally, adherence to treatment was not monitored.

\section{Conclusions}

First-line management of dyslipidemia among very-high cardiovascular risk outpatients in Western Greece is unsatisfactory, with the majority of treated individuals failing to attain the LDL-C and non-HDL-C targets. This observed treatment gap although disappointing, translates into an opportunity to ameliorate clinical outcome of such patients. Therefore, strategies to improve management of dyslipidemia, such as intensification of first-line statin treatment, are necessary.

\section{Competing interests}

Dr Alexopoulos reports receipt of speakerfees from AstraZeneca. This study was supported by the Research Committee of the Patras University Medical school.

\section{Authors' contributions}

Analyzed, interpreted the data and drafted manuscripts: IX, PD, SS, AP and ZE, conception, design and final approval of the manuscript DA. All authors read and approved the final manuscript.

\section{Acknowledgements}

The authors are grateful to the following cardiologists for participating to this study: loannis Christodoulou, Nikolaos Grapsas, Andreas Mazarakis, Georgios Aggelopoulos, Panagiotis Anastopoulos, Ioanna Gerasimidou, Nikolaos Evaggelopoulos, Georgios Karapanos, Nikolaos Karouzos, Andreas Karidakis, Anna Klinaki, Andreas Kotsalos, Chara Krondira, Konstantinos Lampakis, Loukas Martsekis, Georgia Michopoulou, Antonios Mperoukas,
Euxaristi Mpoumpali, Panagiotis Papadionusiou, Andreas Samothrakitis, Christos Stathopoulos, Georgios Stamos, Georgios Sfikas, and GeorgiosTagalakis.

Received: 23 August 2013 Accepted: 5 November 2013

Published: 9 November 2013

\section{References}

1. World Health Organization: World Health Statistics 2013. ; 2013. http://www.who.int/mediacentre/factsheets/fs317/en/index.html.

2. Reiner Z, Catapano AL, De Backer G, Graham I, Taskinen MR, Wiklund O, Agewall S, Alegria E, Chapman MJ, Durrington P, et al: ESC/EAS Guidelines for the management of dyslipidaemias: the task force for the management of dyslipidaemias of the european society of cardiology (ESC) and the European atherosclerosis society (EAS). Eur Heart J 2011 32:1769-1818.

3. Baigent C, Blackwell L, Emberson J, Holland LE, Reith C, Bhala N, Peto R, Barnes EH, Keech A, Simes J, Collins R: Efficacy and safety of more intensive lowering of LDL cholesterol: a meta-analysis of data from 170,000 participants in 26 randomised trials. Lancet 2010, 376:1670-1681.

4. Brugts JJ, Yetgin T, Hoeks SE, Gotto AM, Shepherd J, Westendorp RG, de Craen AJ, Knopp RH, Nakamura H, Ridker $P$, et al: The benefits of statins in people without established cardiovascular disease but with cardiovascular risk factors: meta-analysis of randomised controlled trials. BMJ 2009, 338:b2376

5. Mills EJ, Rachlis B, Wu P, Devereaux PJ, Arora P, Perri D: Primary prevention of cardiovascular mortality and events with statin treatments: a network meta-analysis involving more than 65,000 patients. J Am Coll Cardiol 2008, 52:1769-1781.

6. Grundy SM, Cleeman JI, Merz CN, Brewer HB Jr, Clark LT, Hunninghake DB, Pasternak RC, Smith SC Jr, Stone NJ: Implications of recent clinical trials for the National cholesterol education program adult treatment panel III guidelines. Circulation 2004, 110:227-239.

7. Heart Protection Study Collaborative Group: MRC/BHF heart protection study of cholesterol lowering with simvastatin in 20,536 high-risk individuals: a randomised placebo-controlled trial. Lancet 2002, 360:7-22.

8. Cannon CP, Braunwald E, McCabe CH, Rader DJ, Rouleau JL, Belder R, Joyal SV, Hill KA, Pfeffer MA, Skene AM: Intensive versus moderate lipid lowering with statins after acute coronary syndromes. N Engl J Med 2004, 350:1495-1504

9. Pedersen TR, Faergeman O, Kastelein JJ, Olsson AG, Tikkanen MJ, Holme I, Larsen ML, Bendiksen FS, Lindahl C, Szarek M, Tsai J: High-dose atorvastatin vs usual-dose simvastatin for secondary prevention after myocardial infarction: the IDEAL study: a randomized controlled trial. JAMA 2005, 294:2437-2445.

10. LaRosa JC, Grundy SM, Waters DD, Shear C, Barter P, Fruchart JC, Gotto AM, Greten H, Kastelein JJ, Shepherd J, Wenger NK: Intensive lipid lowering with atorvastatin in patients with stable coronary disease. $N$ Engl J Med 2005, 352:1425-1435.

11. Davidson MH, Maki KC, Pearson TA, Pasternak RC, Deedwania PC, McKenney JM, Fonarow GC, Maron DJ, Ansell BJ, Clark LT, Ballantyne CM: Results of the national cholesterol education (NCEP) program evaluation project utilizing novel E-technology (NEPTUNE) II survey and implications for treatment under the recent NCEP writing group recommendations. Am J Cardiol 2005, 96:556-563.

12. Santos RD, Waters DD, Tarasenko L, Messig M, Jukema JW, Chiang CW, Ferrieres J, Foody JM: A comparison of non-HDL and LDL cholesterol goal attainment in a large, multinational patient population: the lipid treatment assessment project 2. Atherosclerosis 2012, 224:150-153.

13. Grundy SM, Cleeman JI, Daniels SR, Donato KA, Eckel RH, Franklin BA, Gordon DJ, Krauss RM, Savage PJ, Smith SC Jr, et al: Diagnosis and management of the metabolic syndrome: an american heart Association/National heart, lung, and blood institute scientific statement. Circulation 2005, 112:2735-2752.

14. Friedewald WT, Levy RI, Fredrickson DS: Estimation of the concentration of low-density lipoprotein cholesterol in plasma, without use of the preparative ultracentrifuge. Clin Chem 1972, 18:499-502.

15. Waters DD, Brotons C, Chiang CW, Ferrieres J, Foody J, Jukema JW, Santos RD, Verdejo J, Messig M, McPherson R, et al: Lipid treatment assessment project 2: a multinational survey to evaluate the proportion of patients achieving low-density lipoprotein cholesterol goals. Circulation 2009, 120:28-34. 
16. Karalis DG, Subramanya RD, Hessen SE, Liu L, Victor MF: Achieving optimal lipid goals in patients with coronary artery disease. Am J Cardiol 2011, 107:886-890.

17. Rallidis LS, Kotakos C, Sourides V, Varounis C, Charalampopoulos A, Zolindaki M, Dagres N, Papadopoulos C, Anastasiou-Nana M: Attainment of optional low-density lipoprotein cholesterol goal of less than $70 \mathrm{mg} / \mathrm{dl}$ and impact on prognosis of very high risk stable coronary patients: a 3-year follow-up. Expert Opin Pharmacother 2011, 12:1481-1489.

18. Elisaf MS, Nikas N: Centralized Pan-European survey on the undertreatment of hypercholesterolemia in patients using lipid lowering drugs-the CEPHEUS-Greece survey. Angiology 2010, 61:465-474.

19. Tattersall MC, Gangnon RE, Karmali KN, Cullen MW, Stein JH, Keevil JG: Trends in low-density lipoprotein cholesterol goal achievement in high risk United States adults: longitudinal findings from the 1999-2008 national health and nutrition examination surveys. PLoS One 2013, 8:e59309

20. Sager HB, Linsel-Nitschke P, Mayer B, Lieb W, Franzel B, Elsasser U, Schunkert H: Physicians' perception of guideline-recommended low-density lipoprotein target values: characteristics of misclassified patients. Eur Heart J 2010, 31:1266-1273.

21. Hwang JY, Jung CH, Lee WJ, Park CY, Kim SR, Yoon KH, Lee MK, Park SW, Park JY: low density lipoprotein cholesterol target goal attainment rate and physician perceptions about target goal achievement in Korean patients with diabetes. Diabetes Metab J 2011, 35:628-636.

22. Ballantyne CM, Corsini A, Davidson MH, Holdaas H, Jacobson TA, Leitersdorf E, Marz W, Reckless JP, Stein EA: Risk for myopathy with statin therapy in high-risk patients. Arch Intern Med 2003, 163:553-564.

23. Mikhailidis DP, Lawson RW, McCormick AL, Sibbring GC, Tershakovec AM, Davies GM, Tunceli K: Comparative efficacy of the addition of ezetimibe to statin vs statin titration in patients with hypercholesterolaemia: systematic review and meta-analysis. Curr Med Res Opin 2011, 27:1191-1210.

24. Friedman HS, Rajagopalan S, Barnes JP, Roseman H: Combination therapy with ezetimibe/simvastatin versus statin monotherapy for low-density lipoprotein cholesterol reduction and goal attainment in a real-world clinical setting. Clin Ther 2011, 33:212-224.

25. Stein E, Stender S, Mata P, Sager P, Ponsonnet D, Melani L, Lipka L, Suresh R Maccubbin D, Veltri E: Achieving lipoprotein goals in patients at high risk with severe hypercholesterolemia: efficacy and safety of ezetimibe co-administered with atorvastatin. Am Heart J 2004, 148:447-455.

26. Migdalis I, Efthimiadis A, Pappas S, Alexopoulos D, Vlasserou F, Mikhailidis DP: Clinical experience with ezetimibe/simvastatin in a Mediterranean population. Curr Med Res Opin 2009, 25:2571-2576.

27. Yan AT, Yan RT, Tan M, Hackam DG, Leblanc KL, Kertland H, Tsang JL, Jaffer S, Kates ML, Leiter LA, et al: Contemporary management of dyslipidemia in high-risk patients: targets still not met. Am J Med 2006, 119:676-683.

28. Gitt AK, Drexel H, Feely J, Ferrieres J, Gonzalez-Juanatey JR, Thomsen KK, Leiter LA, Lundman P, da Silva PM, Pedersen T, et al: Persistent lipid abnormalities in statin-treated patients and predictors of LDL-cholesterol goal achievement in clinical practice in Europe and Canada. Eur J Prev Cardiol 2012, 19:221-230.

29. Banta MR, Ma F, Bravata DM, Kirsner RS, Federman DG: Incidence of and factors associated with achieving target lipid levels in patients with peripheral arterial disease. J Gen Intern Med 2006, 21:711-714.

\section{Submit your next manuscript to BioMed Central and take full advantage of:}

- Convenient online submission

- Thorough peer review

- No space constraints or color figure charges

- Immediate publication on acceptance

- Inclusion in PubMed, CAS, Scopus and Google Scholar

- Research which is freely available for redistribution

Submit your manuscript at www.biomedcentral.com/submit
C Biomed Central 